\title{
Monitoring the dynamic behaviors of the Bosporus Bridge by GPS during Eurasia Marathon
}

\author{
H. Erdoğan ${ }^{1}$, B. Akpınar ${ }^{2}$, E. Gülal ${ }^{2}$, and E. Ata $^{2}$ \\ ${ }^{1}$ Aksaray University, Aksaray, Turkey \\ ${ }^{2}$ Yıldiz Technical University, Istanbul, Turkey
}

Received: 22 March 2007 - Revised: 25 June 2007 - Accepted: 2 August 2007 - Published: 16 August 2007

\begin{abstract}
Engineering structures, like bridges, dams and towers are designed by considering temperature changes, earthquakes, wind, traffic and pedestrian loads. However, generally, it can not be estimated that these structures may be affected by special, complex and different loads. So it could not be known whether these loads are dangerous for the structure and what the response of the structures would be to these loads. Such a situation occurred on the Bosporus Bridge, which is one of the suspension bridges connecting the Asia and Europe continents, during the Eurasia Marathon on 2 October 2005, in which 75000 pedestrians participated. Responses of the bridge to loads such as rhythmic running, pedestrian walking, vehicle passing during the marathon were observed by a real-time kinematic (RTK) Global Positioning System (GPS), with a 2.2-centimeter vertical accuracy. Observed responses were discussed in both time domain and frequency domain by using a time series analysis. High $(0.1-1 \mathrm{~Hz})$ and low frequencies $(0.00036-0.01172 \mathrm{~Hz})$ of observed bridge responses under 12 different loads which occur in different quantities, different types and different time intervals were calculated in the frequency domain. It was seen that the calculated high frequencies are similar, except for the frequencies of rhythmic running, which causes a continuously increasing vibration. Any negative response was not determined, because this rhythmic effect continued only for a short time. Also when the traffic load was effective, explicit changes in the bridge movements were determined. Finally, it was seen that bridge frequencies which were calculated from the observations and the finite element model were harmonious. But the 9th natural frequency value of the bridge under all loads, except rhythmic running could not be determined with observations.
\end{abstract}

Correspondence to: $\mathrm{H}$. Erdoğan

(hediye.erdogan@gmail.com)

\section{Introduction}

The safety of engineering structures depends on predictions during structure design, observations during construction and management of the structure, and execution of emergency plans during unsystematic movements. Taking the necessary precautions by determining possible accidents in a timely fashion is very important for engineering studies (Heunecke, 2000). So the movement and shape changes of the structures under temperature changes, wind, pedestrian and traffic loads must be measured by the appropriate equipment and must be processed and analyzed.

The working group 6.1 of International Federation of Surveyors commissions has concentrated on the developments of new monitoring systems, using the system theory and signal processing for determining the structural behaviors. Welsch and Heunecke (2001) expressed in their report that behaviors of engineering structures must be discussed with parametric and non-parametric methods in the scope of system identification. Time series analysis (Welsch et al., 2000) is a method of system identification that is frequently applied in non-parametric situations. The most significant information to be calculated in the time domain of a time series is its expectation value and the auto-covariance function. If one applies Fourier transformations to switch from the time domain to the frequency domain, characteristic frequencies of the process can be detected. These frequencies are calculated by using output signals and these output signals are the results of the input signals. Consequently, frequencies, which are in the output but not in the input signal, can give clues that there may be more than just the investigated factors influencing the system (Kuhlmann, 1996).

Large structures, such as long bridges, towers and tall buildings, may vibrate and displace during temperature changes, wind, traffic load changes and earthquakes. To

Published by Copernicus Publications on behalf of the European Geosciences Union and the American Geophysical Union. 
measure the structural vibration and displacement, some traditional geodetic measurement methods, such as accelerometer, laser interferometer and electronic distance measurement, are adopted. These methods have some disadvantages. For example, accelerometers cannot measure the swing of total vibration of the structure because acceleration cannot be truly obtained when the structure moves slowly; laser interferometer and electronic distance measurement instrument are limited by climate condition, i.e. a clear line of sight is the basic condition in which they can work (Lovse et al., 1995).

GPS technology not only overcomes the limitation of climate, but also measures the structure displacement in threedimensional directions. Mm-level accuracy can be obtained by using a differential GPS carrier-phase approach and the sampling frequency of $10 \mathrm{~Hz}$ or $20 \mathrm{~Hz}$ are now available from GPS receivers. All these improvements provide a great opportunity to monitor the dynamic characteristics of large structures in real-time or near real-time (Cheng et al., 2002; Lovse et al., 1995).

Some of the important studies about monitoring the engineering structures, especially about monitoring the bridges, by using geodetic measurement methods, are given below. For example, determination of the dynamic deformation measurements of the Calgary Tower in Canada with a GPS (Lovse et al., 1995), studies performed on the Humber Bridge (Roberts et al., 1999), studies about monitoring the engineering structure movements with GPS, especially by selecting the sampling frequency (Roberts et al., 2000), monitoring the movements of Tsing-Ma, Kap Shui Mun and Ting Kua Bridges in Hong-Kong with GPS (Wong, 2000), determining the effects of wind forces and pedestrian load on the Nottingham Human Bridge with GPS and accelerometer (Roberts et al., 2001) and monitoring the movements of the Nesenbachtal Bridge in Germany with a reflectorless total station (Kuhlman, 2001).

We attempt to explain behaviors of the Bosporus Bridge under different loads in this paper. As it is known, suspension bridges, like the Bosporus Bridge, are designed by considering the possible responses under different loads, such as temperature changes, wind, traffic and pedestrian loads, earthquakes and snow. Special conditions, such as rhythmic running, may be neglected during these considerations, thus, a problem may occur: What are the responses of complex structures like suspension bridges under this type of special load? For investigating this problem, observations on the middle point of a bridge were done during the 27th Intercontinental Eurasia Marathon on 2 October 2005. The RTK GPS method was used for determining the bridge's behavior during rhythmic running, pedestrian walking (unsystematic pedestrian load) and when the bridge was closed to pedestrian and vehicle traffic. Observations were divided into 12 parts, depending on the loads and frequencies of each part.

\section{Method}

Characteristics of the time series can be summarized and the outstanding structure of the series can be exposed by using a time series analysis which is obtained by monitoring the responses of engineering structures. So behaviors (linear, periodical) of the monitored system under different loads can be explained by using a time series analysis. This process is discussed both in time domain and in frequency domain. In other words, periodical movements are discussed in frequency domain and relations between different times are discussed in time domain. Each analysis is complementary to each other and the same information gives different ideas about the characteristics of the time series.

Generally, the $Y\left(t_{i}\right)$ time series of observations on $t_{i}(i=1$, $2,3, \ldots, N$ ) time is divided into 3 components:

$Y\left(t_{i}\right)=Y\left(t_{i}\right)_{\text {Trend }}+Y\left(t_{i}\right)_{\text {Periodical }}+Y\left(t_{i}\right)_{\text {Stochastic }}$.

By partitioning these components of the series, structural behaviors can be explained with information about the dynamic characteristics of the series. Structural movements are obtained as frequency information by spectral analysis, which is used for studying the frequency characteristics and defined in frequency domain. Firstly, the time axes graphic of the series is drawn and extraordinary observations are eliminated in the time series analysis. And then, components of the series (trend, periodical component etc.) are determined by a time series analysis.

For eliminating the noise in the series and for bringing up the trend and periodical components (low frequency variation) the series must be first smoothed in a time series analysis. A 5th order floating weighted average method is often used for determining the periodical component in short time observations in smoothing process. This process also shows a low-pass-filtering characteristic.

$Y\left(t_{i}\right)=\left(Y\left(t_{i}\right)+4 Y\left(t_{i+1}\right)+6 Y\left(t_{i+2}\right)+4 Y\left(t_{i+3}\right)+Y\left(t_{i+4}\right) / 16\right)$

Later it is determined if there is a trend component in the series. An existing trend component in the series represents the long time changes in the series and is defined as a polynomial function which is given below:

$Y\left(t_{i}\right)_{\text {Trend }}=\sum_{k=1}^{m} c_{k} t_{i}^{k-1}$,

where $c_{k},(k=1,2, \ldots, m)$ are the parameters which depend on a function degree. Yong and Chrzanowski (1996) discussed the trend component in a series as a kinematical trend, namely long time changes in the structure.

The periodical component in the series is analyzed after the trend component analysis in the series. It is considered that the periodical component in the series, which is obtained by continuously monitoring of the engineering structures, is derived from the periodical response of the structure under 
periodical loads. For example; long time periodical movements may be observed on engineering structures, depending on temperature changes (day-night, seasonable). Depending on traffic load, approximately the same number of vehicles pass through the suspended bridges almost every day, approximately at the same time. In particular changes, in vehicle numbers occur during nights (decreasing) and days (increasing). Depending on these changes in vehicle numbers, a lot of periodical movements (max. period is $24 \mathrm{~h}$ ) can be seen on bridges. However, vehicle type and travel speed cause short-time periodical movements and instantaneous vibrations. These types of responses are discussed commonly for investigating the bridge behaviors (Erdoğan et al., 2005).

The periodical component in the series can be modeled by a trigonometric function, which is given in Eq. (4), depending on $f_{s}(s=1,2, \ldots, p)$ frequencies and $Y\left(t_{i}\right)$ observations:

$Y\left(t_{i}\right)_{\text {Periodical }}=\sum_{s=1}^{p}\left[a_{s} \cos \left(2 \pi f_{s} t_{i}\right)+b_{s} \sin \left(2 \pi f_{s} t_{i}\right)\right]$.

Amplitude $(R)$ of the periodical movement is defined as Eq. (5) with $a_{s}$ and $b_{s}$ parameters:

$R=\sqrt{a_{s}^{2}+b_{s}^{2}}$.

The general definition of the time series is given in Eq. (6) by using the trend in Eq. (3) and periodical component functions in Eq. (4):

$$
\begin{aligned}
& Y\left(t_{i}\right)=\sum_{k=1}^{m} c_{k} t_{i}^{k-1}+ \\
& \cdot \sum_{s=1}^{p}\left[a_{s} \cos \left(2 \pi f_{s} t_{i}\right)+b_{s} \sin \left(2 \pi f_{s} t_{i}\right)\right]+Y\left(t_{i}\right) \text { Stochastic }
\end{aligned}
$$

Figure 1 shows the components of the time series in Eq. (6) and the effect of the method used in the data analysis.

The time series in Fig. 1 consists of the time-dependent observations of linear and periodical movements on the engineering structures under temperature, wind and traffic load. This time series also includes random errors which occur during observations. Structural movements represented by the series can be determined by finding the trend, as well as the periodical and stochastic components of the series by analyzing the series in figure.

Equation (3) and Eq. (4) or Eq. (6) is used for determining the trend and periodical component of the time series (raw data) in Fig. 1. $c_{k}, a_{s}$ and $b_{s}$ are unknown parameters in Eqs. (3) and (4) and the covariance matrix of these parameters are estimated by a Least-Squares Method (LSM). The square roots of the diagonal elements of this matrix are estimates of the standard deviations of the parameters. Test values are calculated by using estimated $c_{k}, a_{s}$ and $b_{s}$ parameters, and $m_{\mathrm{ck}}, m_{\mathrm{as}}$ and $m_{\mathrm{bs}}$ standard deviations. Test values for every parameter are given below:

$\hat{t}_{\mathrm{ck}}=\frac{c_{k}}{m_{\mathrm{ck}}} ; \quad \hat{t}_{\mathrm{as}}=\frac{a_{s}}{m_{\mathrm{as}}} ; \quad \hat{t}_{\mathrm{bs}}=\frac{b_{s}}{m_{\mathrm{bs}}}$.

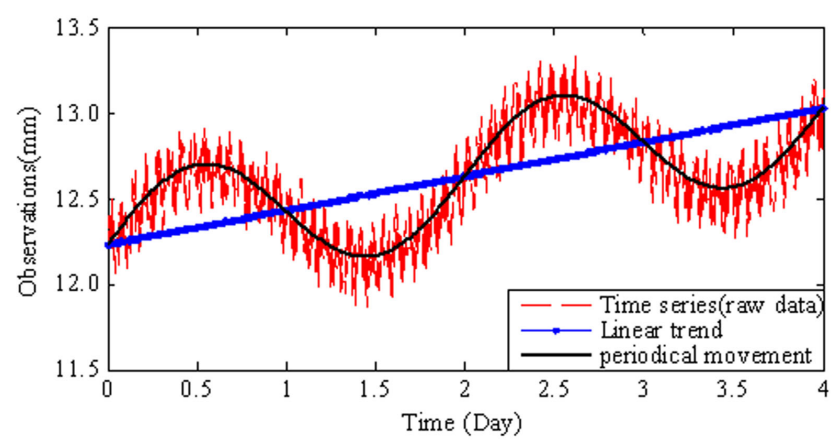

Fig. 1. $Y\left(t_{i}\right)$ time series (raw data), trend and periodical components of this series (example).

These test values are compared with a $t_{f, 1-\alpha / 2}$ confidence limit of the t-distribution, depending on the $1-\alpha$ confidence level and a $f=n-u$ (the number of observations - the number of unknown parameters) degree of freedom. For the trend component,

$$
\text { If }\left|\hat{t}_{c k}\right|<t f, 1-\alpha / 2 \text {, the } \mathrm{c}_{k} \text { parameter is insignificant, }
$$

otherwise it is significant.

For periodical components,

If $\left|\hat{t}_{a s}\right|>t_{f, 1-\alpha / 2}$ or $\left|\hat{t}_{b s}\right|>t_{f, 1-\alpha / 2}$; or If $\left|\hat{t}_{a s}\right|>t_{f, 1-\alpha / 2}$ and $\left|\hat{t}_{b s}\right|>t_{f, 1-\alpha / 2} ; \mathrm{a}_{s}, \mathrm{~b}_{s}$ parameters are significant,

If $\left|\hat{t}_{a s}\right|<t_{f, 1-\alpha / 2}$ and $\left|\hat{t}_{b s}\right|<t_{f, 1-\alpha / 2} ; \mathrm{a}_{s}, \mathrm{~b}_{s}$ parameters are insignificant.

After the test, insignificant parameters are removed from the function and the process is continued until all the parameters become significant.

For determining the periodical movement in the function expressed in Eq. (4), low frequencies (slow vibrations) of this movement must be known. Therefore, first, the trend component of the series must be determined by Eq. (3) and if the parameters become significant, it must be eliminated from the series. Otherwise, the trend component of the series will affect the spectral analysis results and it will have a peak value on a zero frequency (Chatfield, 1996).

For the transform of the series from a time domain to frequency domain, a Fast Fourier Transform (FFT) is used. FFT is not different from the Discrete Fourier Transform (DFT). It is an effective and perfect algorithm for calculating the DFT. But DFT has periodical characteristics and is processed as if the first signal pattern comes after the last signal pattern in spectrum calculations. Under these circumstances signal energy leaks other frequencies and spectral leakage occurs. For reducing this effect, the signal is multiplied with a windowing function, whose amplitude approaches zero at the edges. So the lack of continuity between the last and first values of signal can be removed. Hamming, Kaiser, Blacman, Barttlett and Hanning windowing functions are usually used for this purpose (Chatfield, 1996). For example, the 
Hanning Windowing Function is expressed as Eq. (8) where the $N$ is the number of observations:

$w(i)=0.5-0.5 \cos \left(\frac{2 \pi i}{N}\right)$.

$Y\left(t_{i p}\right)$ observations are multiplied with $w(i)$ Hanning Windowing Function. If FFT (Fast Fourier Transform) is applied to these $Y\left(t_{i p}\right)=Y\left(t_{i}\right) . \quad w(i)$ windowed observations, $X(k)$ FFT coefficients in Eq. (10) are obtained.

$X(k)=\sum_{t_{i}=0}^{N-1} Y\left(t_{i p}\right) \cdot e^{-j k \frac{2 \pi}{N} t_{i}}$

For $0 \leq k \leq N-1$, the calculation of $X(k)$ in Eq. (9) requires $N$ complex multiplications and $N-1$ complex sums. Computing all $N$ of the $X(k)$ values demands $N^{2}$ complex multiplications and $N^{2}-N$ complex additions. The FFT coefficients $X(k)$ do not aid interpretation because these values are complex numbers. Therefore, the power of the FFT signal is expressed below:

$P_{x x}(k)=|X(k)|^{2}$,

where $\mathrm{P}_{x x}(\mathrm{k})$ describes the distribution (over frequency) of the power contained in a signal (Allen and Mills, 2004).

Periodical movement parameters $\left(a_{s}\right.$ and $\left.b_{s}\right)$ of the function expressed in Eq. (4) are estimated by LSM. Insignificant parameter frequency is removed from the function and this process is continued until the significant frequencies are determined (It is enough if one of the parameters becomes significant). THe deterministic part of the series is reached by adding the periodical movements and trend component in Eq. (6).

Besides determining the significant low frequencies in the series, local changes, namely, high frequency variations, must be determined, because depending on the high frequency (fast vibration), instantaneous or random loads, structures like suspension bridges respond at high frequencies. These types of changes can be determined by using Eqs. (8), (9) and (10). But first a simple filtering (high-pass) process based on the differencing method must be applied to the series. If the $Y\left(t_{i}\right)$ is the observation values of the series, a $d$. degree differencing process is applied and a new series is formed. A 1st order differencing is expressed in Eq. (11):

$\nabla Y\left(t_{i+1}\right)=Y\left(t_{i+1}\right)-Y\left(t_{i}\right)$.

By differencing the series, noise effects on the series are decreased and a stationary series can be obtained by removing the trend component (Box and Jenkins, 1970).

At last, the $Y\left(t_{i}\right)_{\text {Stochastic }}$ stochastic component of the series is analyzed in time series analysis. In this study, low frequencies and high frequencies were studied by means of time series analysis. So, stochastic component analysis of the series could not be expressed in this study.

\section{Material}

\subsection{Bridge description}

The Bosporus Bridge links two parts of Turkey and also connects the European and Asia parts of Istanbul. The project of the Bosporus Suspension Bridge was designed in 1969 and its construction started in 1970. It was completed and went into use in 1973. It has a $1074 \mathrm{~m}$ main span and $231 \mathrm{~m}$ and $255 \mathrm{~m}$ side spans on the European and Asian sides, respectively. The deck of the Bosporus Bridge is a hollow box construction and hangers ensure the suspension of the deck. Bosporus Bridge's hangers are of the inclined type. Bridge towers are a steel box construction and are $165 \mathrm{~m}$ high.

Bosporus Bridge was designed to carry 6 lanes of highway traffic. English traffic load standards were used with an additional $10 \%$ increase in values and a 180 tone special vehicle load was accepted as traffic load for Bosporus Bridge. Maximum wind speed was accepted as $45 \mathrm{~m} / \mathrm{sec}$ for the wind load and the project temperature was accepted as $20^{\circ} \mathrm{C}$.

\subsection{Bosporus bridge trials}

A research group from Yıldız Technical University, Division of Surveying Techniques, is undertaking on a comprehensive project for determining the behaviors of the Bosporus Bridge. In this project, behaviors of the bridge under temperature changes, wind and traffic loads were investigated based on time and frequency domains.

In the first phase of this project, terrestrial observations had been executed in partnership with Universität der Bundeswehr München Institut für Geodäsie by using the ATR system Total Station (Leica TCA2003) between 22 September 2003-26 September2003. Behaviors of the bridge under usual loads had been investigated during this phase. In the second phase, behaviors of the bridge under different loads had been investigated. The RTK GPS method was used for this purpose on 02 October 2005 during the 27 th Intercontinental Eurasia Marathon. Eventually in the third phase, behaviors of the bridge under usual loads had been investigated by using long time RTK GPS observations between 02 June 2006-12 June 2006.

In this paper, behaviors of the Bosporus Bridge under different loads during the Eurasia Marathon were investigated. This study is also the 2 nd phase of the project mentioned above.

It is not possible to compare the RTK GPS method used for determining the bridge behaviors in this paper (also 2nd phase of the project) with terrestrial methods used in the 1st phase of the project, because the observation times of these phases were different. However, for making a general comparison, low and high frequencies of the terrestrial observations were calculated and the results were given in the following parts. 
Table 1. \pm Maximum changes of the Bosporus Bridge for 12 parts according to mean value.

\begin{tabular}{|c|c|c|c|c|}
\hline $\begin{array}{l}\text { Part } \\
\text { no. }\end{array}$ & Load & $\begin{array}{l}\text { Maximum } \\
\text { changes above } \\
\text { mean movement } \\
\text { level }(\mathrm{mm})\end{array}$ & $\begin{array}{l}\text { Maximum } \\
\text { changes below } \\
\text { mean movement } \\
\text { level }(\mathrm{mm})\end{array}$ & $\begin{array}{l}\text { Amplitude } \\
\text { values for } \\
\text { maximum } \\
\text { periodical } \\
\text { movements }(\mathrm{mm})\end{array}$ \\
\hline 1 & Low vehicle load & +117 & -18 & 46.7 \\
\hline 2 & Empty 1 & +132 & - & 7.3 \\
\hline 3 & Marathon (rhythmic run) & +131 & - & 21.2 \\
\hline 4 & 11 buses + pedestrian & +159 & -169 & 100.4 \\
\hline 5 & Pedestrian activities & +131 & -19 & 19.5 \\
\hline 6 & Low pedestrian load & +8 & -81 & 13.8 \\
\hline 7 & Pedestrian + vehicle & +63 & -303 & 206.6 \\
\hline 8 & Low pedestrian load & +95 & -35 & 23.1 \\
\hline 9 & Buses + trucks + pedestrians & +64 & -28 & 34.1 \\
\hline 10 & Empty 2 & +118 & -28 & 17.7 \\
\hline 11 & Traffic on the North Side & +120 & -16 & 18.3 \\
\hline 12 & Opened for traffic & +116 & -390 & 51.5 \\
\hline
\end{tabular}

Thales Z-Max GPS receivers were used for observations on the bridge during the Marathon. Then 2-Hz sampling frequency was chosen for these observations. The Thales ZMax GPS receiver has a nominal accuracy of $\pm 1 \mathrm{~cm}+1 \mathrm{ppm}$ for horizontal displacements and $\pm 2 \mathrm{~cm}+2 \mathrm{ppm}$ for vertical displacements, with a sampling rate of $10 \mathrm{~Hz}$. The reference point (P7) is on a building approximately $1 \mathrm{~km}$ away from the bridge. The middle point of the deck (number 22) was chosen as an object point where maximum vertical movement was expected. Reference point (P7) and object point (22) are shown in Fig. 2. RTK GPS measurements had been taken between 08:45-13:15 during all the activities. During the observations, the average temperature change was $2^{\circ} \mathrm{C}$, wind speed change was $2.5 \mathrm{~m} / \mathrm{sec}$ in the North direction. In addition, rain for different densities was observed during the measurements.

\section{Analysis of observations and results}

Substantial changes in the horizontal direction could not be determined by processing the observations. The largest movements occurred in the vertical direction on these types of structures because of the wide main span. Therefore, vertical changes in the bridge were processed and analyzed in this study.

The 4.5-h total observation time was divided into 12 parts for determining the responses which occurred due to the rhythmic running, traffic and pedestrian loads during the marathon activities (Table 1 and Fig. 3). There were specific loads in every part. Local changes in every part (high frequency variations or fast vibrations) and long time changes during every part of the 12 sections were processed and ana-

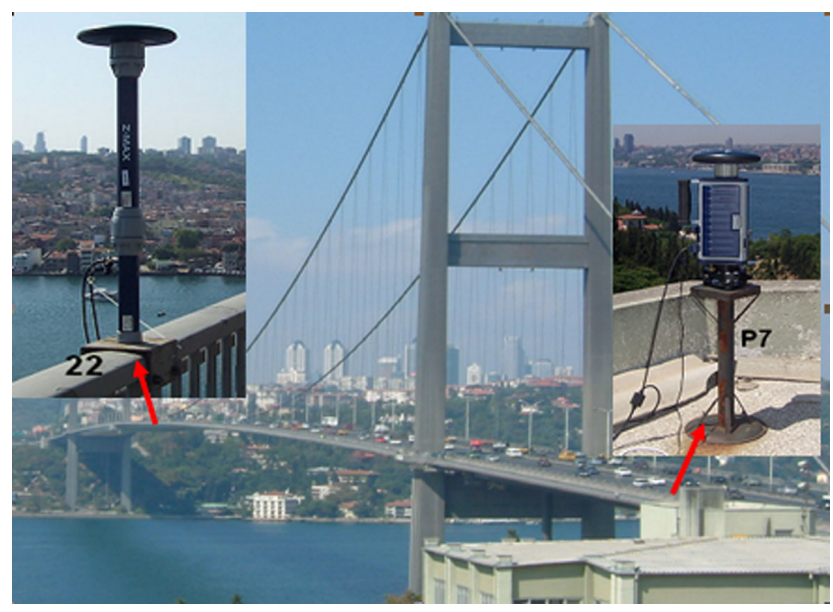

Fig. 2. Reference (P7) and object (22) points used on Bosporus Bridge during Eurasia Marathon.

lyzed. In addition, it was assumed that no change occurred in temperature and wind force values during the observations. Figure 3 shows a time series graphic of the differences in the vertical changes from the mean value (by using raw data). Maximum changes in each part below (-) and above (+) the mean value were given in Table 1 .

Also, behaviors of the Bosporus Bridge according to the mean level during marathon were explained depending on Fig. 3 and Table 1.

- In the first part, the bridge was closed to traffic, thereby decreasing the traffic load, and the bridge clearly responded at $117 \mathrm{~mm}$ above the mean level. In the second part, bridge was completely empty and it responded at 


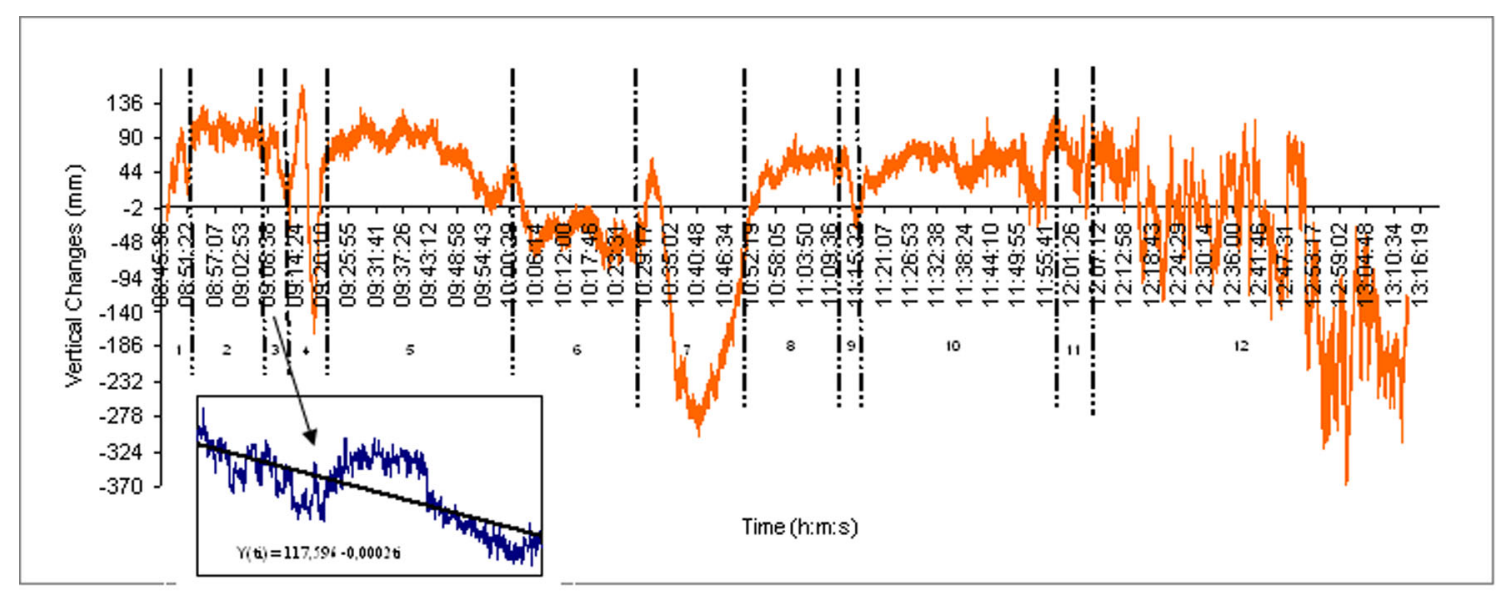

Fig. 3. Vertical changes in the Bosporus Bridge during the Eurasia Marathon.

$132 \mathrm{~mm}$ above the mean level. In the third part, the bridge was affected by a different load. In this part, the effect of the rhythmic running can be seen $(131 \mathrm{~mm})$. The periodical movement caused by this effect was in a different direction, due to the short time period. After the rhythmic running, pedestrian walking had begun and also 11 buses and pedestrians were caused a $169 \mathrm{~mm}$ response below the mean level and a $159 \mathrm{~mm}$ response above mean level (4th), respectively. In this part the bridge behaved periodically at the mean level. The response below the mean level shows that the traffic load affected the bridge, because the bridge behaved below the mean movement level in the 7 th $(-303 \mathrm{~mm})$, 9th $(-$ $28 \mathrm{~mm}), 11$ th $(-16 \mathrm{~mm})$ and 12 th $(-390 \mathrm{~mm})$ parts. It was seen that the traffic load was affected during these responses. In the fifth and sixth parts, there were different activities on the bridge (walking, running, and other activities) and response values are $131 \mathrm{~mm}$ above and $-81 \mathrm{~mm}$ below the mean level. In the eighth and tenth parts, pedestrians were removed and the bridge was empty. In these parts, bridge behaved above the mean level. A similar situation was observed in the first and second parts. When the bridge was opened for traffic in the eleventh and twelfth parts, the bridge responded periodically as $-390 \mathrm{~mm}$ below and $116 \mathrm{~mm}$ above the mean level.

According to the results in Table 1 and Fig. 3, it was seen that the bridge's responses under vehicle load were clearer than other loads (parts 4, 7 and 12).

Information resulting from the measurements on structures is transformed from a time domain to a frequency domain. For some applications the necessary information about the structure is in the high and low frequency information. In this case the time series which represents the system's behaviors is transformed to a frequency domain by FFT, and the system is defined. 5th order floating weighted averages of the series were calculated by Eq. (2) before transforming the series to a frequency domain for determining the periodical movements. In other words, low-pass filtering was applied to the series. Noise effects in the series were removed partly and periodical movements in the series were determined by using this filtering process. Also, any series with uncompleted periodical movements was multiplied by a Hanning Windowing Function (Eq. 8) and the effect of the possible spectral leakage was reduced. Periodical movement(s), namely, low frequencies, was determined by calculating the power spectrums (Eq. 10) of the series by FFT (Eq. 9). But the series had to be stationary (not include trend component) in this process. The existence of the trend component in the series was investigated for making the series stationary. By using Eq. (3), the $c_{1}$ and $c_{2}$ parameters of $Y\left(t_{i}\right)_{\text {Trend }}=c_{1}+c_{2} . t_{i}$ type linear trend component and covariance matrixes of the parameters were predicted by LSM.

Test values from the $c_{1}, c_{2}$ parameters and $m_{c 1}, m_{c 2}$ standard deviations of these parameters were calculated by Eq. (7). These values were compared with $95 \%$ confidence level and $t_{f, 1-0,05 / 2}$ confidence limit of the t-distribution, depending on $\mathrm{f}$ degrees of freedom. The confidence limit of t-distribution for $f>500$ on the $95 \%$ confidence level is 1.96 , because the measurement number in all the series is more than 480 . Test values of the trend component parameters were determined to be bigger than the 1.96 table value. So, significant linear trend components in both the increasing and decreasing directions were determined for the series, obtained for 12 parts.

But this trend component in the series was the result of the uncompleted periodical movements in the short time observations. For example, as seen in Fig. 3, long time periodical movements of the structure occurred as a trend because of the rhythmic running of the athletes in a short time interval in the third part. Increasing or decreasing trends occurred in 
all parts because of these types of changes. If the observation time is short, these situations may occur on structures which have long time periodical movements. 5 th order floating weighted averages of the series were calculated for determining the short time periodical movements of the time series whose trend component was eliminated. In other words, a low-pass filtering process was applied to the series. Low frequencies of the new series, which were obtained after the filtering process were determined by using Eq. (8), Eq. (9) and Eq. (10). The $\mathrm{a}_{s}$ and $\mathrm{b}_{s}$ coefficients of the function expressed in Eq. (4) and the $m_{\text {as }}$ and $m_{\text {bs }}$ standard deviations of these coefficients were estimated by using LSM. The $\hat{t}_{\text {as }}$ and $\hat{t}_{\mathrm{bs}}$ test values were calculated for every coefficient and these values were tested according to a t-distribution on $\alpha=0.05$ error probability. Frequencies of insignificant coefficients were removed from the function. Thus, the frequencies of the function of which all coefficients are significant were accepted as significant periodical movements of the structure.

As a result of the analysis, significant periodical movements were determined in every series, on different numbers between $0.00036-0.01172 \mathrm{~Hz}$. Linear trend components which were removed from the series were added to these periodical movements. Thus, the $Y\left(t_{i}\right)=\sum_{k=1}^{m} c_{k} t_{i}^{k-1}+\sum_{s=1}^{p}\left[a_{s} \cos \left(2 \pi f_{s} t_{i}\right)+b_{s} \sin \left(2 \pi f_{s} t_{i}\right)\right]$ model was obtained. Figure 4 shows the compatibility of the calculated movements from this model and the observations.

According to Fig. 4, these periodical movements were determined:

- Two significant periodical movements on $0.00391 \mathrm{~Hz}$ and $0.00586 \mathrm{~Hz}$ frequencies in the 1 st part where the traffic load is low. Three significant periodical movements on $0.00391 \mathrm{~Hz}, 0.00781 \mathrm{~Hz}$ and $0.01172 \mathrm{~Hz}$ frequencies in the 2 nd part where the bridge was completely closed for traffic. Two significant periodical movements on $0.00391 \mathrm{~Hz}$ and $0.01172 \mathrm{~Hz}$ frequencies in the 3rd part where the rhythmic running was effective. A complete periodical movement on the $0.00293 \mathrm{~Hz}$ frequency was obtained in the 4th part, after the rhythmic running when the pedestrian walk began and vehicles were allowed for emergency. No periodical movements were obtained in the 7 th part when the pedestrian and vehicle numbers began to decrease and in the 9th part when the bridge was almost empty. Four significant periodical movements on $0.00049 \mathrm{~Hz}$, $0.00147 \mathrm{~Hz}, 0.00244 \mathrm{~Hz}$ and $0.00464 \mathrm{~Hz}$ frequencies in the 5 th part and three significant periodical movements on $0.00098 \mathrm{~Hz}, 0.00342 \mathrm{~Hz}$ and $0.00928 \mathrm{~Hz}$ frequencies in the 6 th part were determined. In these parts, there were different activities on the bridge such as walking, running and different and etc. The bridge was almost empty in both the 8th and 10th parts. Two significant periodical movements on $0.000488 \mathrm{~Hz}$, and $0.00293 \mathrm{~Hz}$ frequencies in the 8th part and two significant periodical movements on $0.000977 \mathrm{~Hz}$ and $0,002197 \mathrm{~Hz}$ frequencies in the 10th part were determined. Three significant periodical movements on $0.001953 \mathrm{~Hz}, 0.007813 \mathrm{~Hz}$ and $0.01953 \mathrm{~Hz}$ frequencies in the 11th part when the one-way vehicle pass was allowed and six significant periodical movements on $0.000366,0.001343$, $0.002319,0.003418,0.005615$ and $0.00647 \mathrm{~Hz}$ frequencies in the 12th part when the two-way vehicle pass was allowed were determined.

On the first phase of the project mentioned above, eight significant periodical movements were obtained by using terrestrial observations on the same point (Number 22). Frequencies of these periodical movements are: $0.0009766 \mathrm{~Hz}, 0.003906 \mathrm{~Hz}, 0.007813 \mathrm{~Hz}, 0.01172 \mathrm{~Hz}$, $0.01855 \mathrm{~Hz}, 0.02637 \mathrm{~Hz}, 0.03027 \mathrm{~Hz}, 0.03418 \mathrm{~Hz}$. Depending on the observation time, the biggest periodical movement was obtained on the 1024 th second $(0.0009766 \mathrm{~Hz})$. These movements were obtained under daily traffic load (Fig. 6b). Consequently, it was observed that the traffic load caused much more periodical movement than other loads in the 12th part, which has the most significant periodical movements. And also it was seen that in the other parts the traffic load was not effective as much as in the 12th part. In these parts, periodical movement number $(2,3$ or uncompleted periodical movement) was less than the number in the 12th part.

Besides, the amplitude value $\left(\mathrm{R}_{\max }(\mathrm{mm})\right)$ of the frequency, which has the maximum peak, was calculated from these periodical movements. Calculated amplitudes for every part were given in Table 1. When Fig. 4 and Table 1 are examined, it can be seen that the traffic load was effective in the parts which have high amplitude and the traffic load was not effective even when the bridge was empty (including temperature changes and wind force) in the parts which have low amplitude.

Fast vibrations occur on the bridges because of the random or instantaneous changes in the structural loads (direction changes in the wind, different vehicle speed and breaks, rhythmic or unsystematic walks). We can discuss these kinds of changes as high frequencies on long time changes.

Differencing process was applied to the time series by using Eq. (11) for determining the structural vibrations. In other words, a high-pass filtering process was applied to the series. Thus, high frequencies were determined by eliminating the low frequencies. Also, the trend component of the series was removed completely and the noise effect was partly eliminated.

The differenced series was multiplied by a Hanning Windowing Function. FFT was applied to these multiplied values and then power spectrums of the series were calculated. High frequencies for the twelve parts were shown in Fig. 5. Also, frequency values which have a maximum peak were given in Fig. 5. 

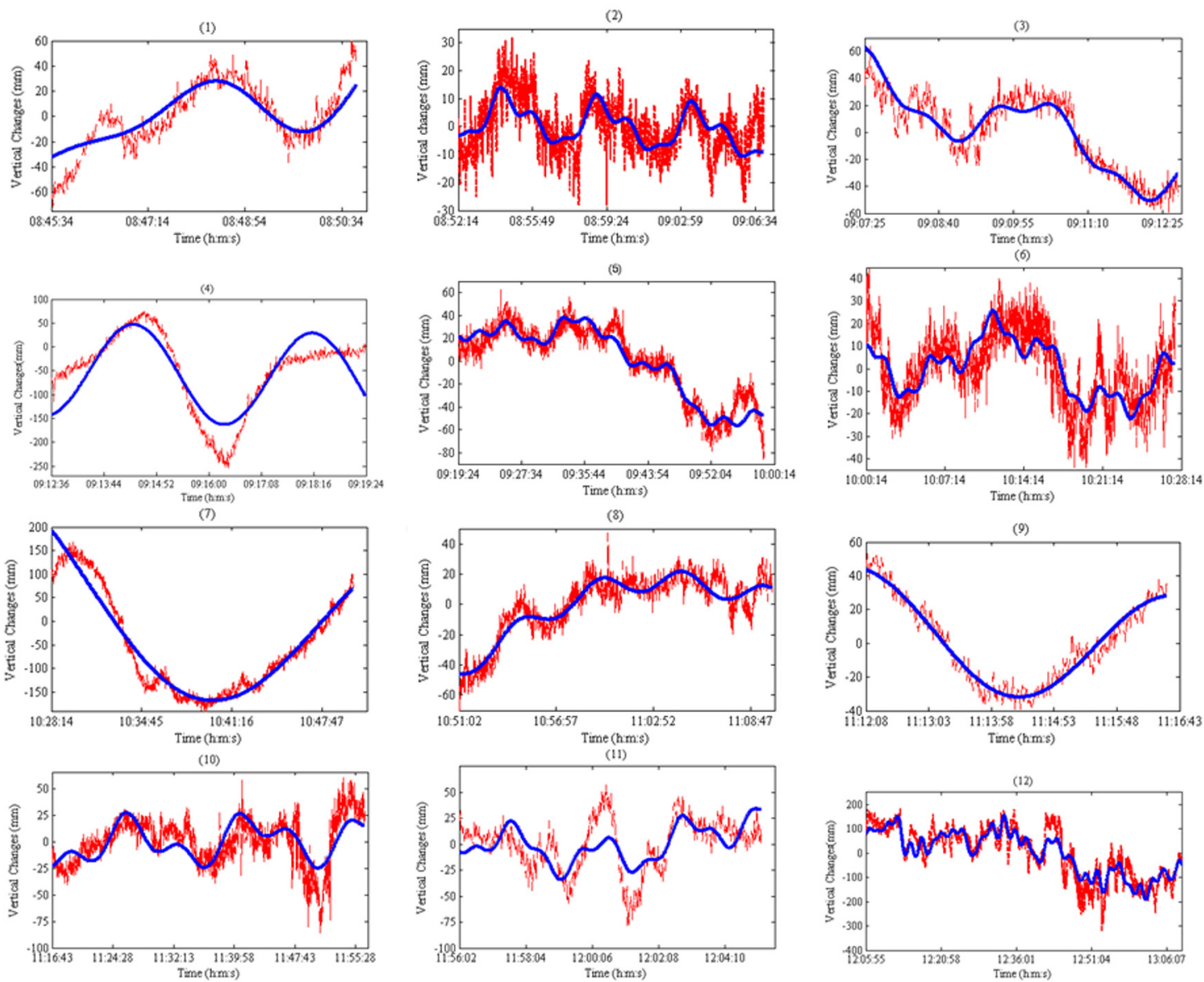

Fig. 4. Responses of the bridge which were calculated with the use of observations (--) and observed bridge responses (--).

According to Fig. 5,

- In the 1st part when the low traffic load was effective, $0.256 \mathrm{~Hz}$, in the 2nd part when the bridge was closed for traffic, $0.264 \mathrm{~Hz}$, and in the 5th part when the pedestrian load was effective, $0.250 \mathrm{~Hz}$, maximum peaks were determined. In the 3 rd part, bridge behaviors were determined as continuously increasing vibration under the rhythmic running effect. The frequency value of maximum peak is $0.900 \mathrm{~Hz}$. The effect of this load walk occurred in a short time period and unsystematic pedestrian walk started after this short time load. Therefore, no dangerous situation occurred on the bridge. Otherwise, if the vibration of rhythmic running and the natural vibration of the bridge coincided, considerable vibration problems could have occurred on the bridge. In this kind of situation, the effect of coercive forces may increase and some risks may occur for the bridge. In the 4 th part, during the pedestrian walk and when the vehicle pass was allowed, the frequency value of maximum peak was determined as $0.852 \mathrm{~Hz}$. Vibrations between $0.125-0.6 \mathrm{~Hz}$ and $0.75-1 \mathrm{~Hz}$ were determined in this part. In the 6th part when the low pedestrian load was effective, $0.162 \mathrm{~Hz}$, in the 7th part when the pedestrian and vehicle loads were effective together, $0.233 \mathrm{~Hz}$, in the 8th part when the pedestrian load decreased, $0.296 \mathrm{~Hz}$, in the 9th part when the traffic and pedestrian loads were effective, $0.207 \mathrm{~Hz}$, and in the 10th part when the bridge was closed to traffic, $0.190 \mathrm{~Hz}$, maximum peak values were determined. In the 11th part when the one-way vehicle pass was allowed and in the 12th part when the two-way vehicle pass was allowed, maximum peak values were determined as $0.215 \mathrm{~Hz}-0.214 \mathrm{~Hz}$, respectively. Both oneway and two-way vehicle passes can cause similar vibrations on the bridge.

Calculated frequencies with the use of terrestrial observations are shown in Fig. 6a. Maximum peak value $0.280 \mathrm{~Hz}$ is equivalent to the 4 th natural frequency value $0.288 \mathrm{~Hz}$. Small peaks between $0.1 \mathrm{~Hz}-0.25 \mathrm{~Hz}$ and prominent peaks between $0.25 \mathrm{~Hz}-0.5 \mathrm{~Hz}$ were determined by using terrestrial observations. It can be said that these values reflect the projected natural frequencies between $0.127 \mathrm{~Hz}-0.463 \mathrm{~Hz}$. Sampling 


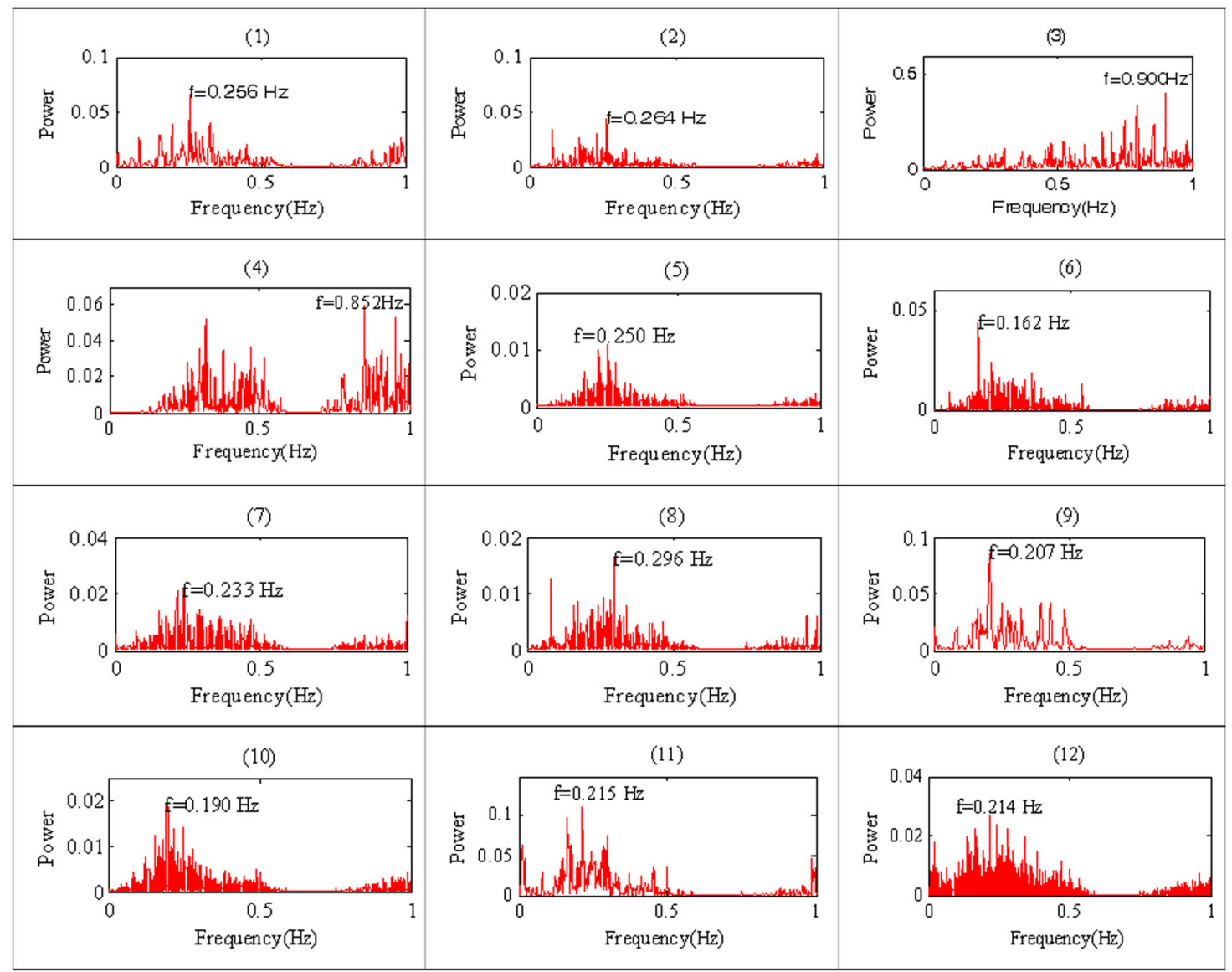

Fig. 5. High frequencies of the bridge which were calculated under different loads during the marathon (the sampling frequency is $2 \mathrm{~Hz}$ ).

frequency of terrestrial observations was $1 \mathrm{~Hz}$ (Maximum sampling frequency of TCA2003), which is why the high frequencies were discussed between $0-0.5 \mathrm{~Hz}$. Prominent peaks between $0-0.06 \mathrm{~Hz}$ were discussed as low frequencies of the bridge (Fig. 6b).

When all the graphics are examined, similar vibrations can be seen in all parts except for the 3rd part. It can bee seen that frequency values are between $0 \mathrm{~Hz}-0.6 \mathrm{~Hz}$ and $0.75 \mathrm{~Hz}-1 \mathrm{~Hz}$ except for the 3 rd and the 4th parts. Frequency values in the 3rd part are increasing and bigger than frequency values in other parts. It can be said that in this part the response of the bridge occurred because of the rhythmic running of the athletes.

Also, natural frequencies of the Bosporus Bridge for the first 11 modes were calculated by Dumanoğlu and Severn (1985) using Finite Elements Method from SAP90 formed model. These frequency values were in the order: 0.127 , $0.165,0.226,0.288,0.378,0.463,0.570,0.573,0.677,0.788$, $0.913 \mathrm{~Hz}$. In other words, the first 11 natural frequency values of the structure are between $0.127 \mathrm{~Hz}-0.913 \mathrm{~Hz}$.

Natural frequencies and periods were determined as a result of the undamped free vibration by considering only the mass matrixes (namely, the mass of the structure) and rigidity matrixes (namely, a matrix formed with material characteristics). So the calculation of the natural frequency of one structure is independent from other loads (wind, earthquake, vehicle load). Dumanoğlu and Severn (1989) showed that mode types and frequencies can be determined as a result of measurements of the temporary vibrations which occur because of wind and traffic load. They chose the Bosporus and Humber Bridges as case studies.

The frequency values which were calculated from observations are in correspondence with the natural frequencies of the bridge. But it is impossible to be informed about the 9th mode frequency value $(0.677 \mathrm{~Hz})$ of all parts except for the $3 \mathrm{rd}$ part which was expected to be between $0.6 \mathrm{~Hz}-0.75 \mathrm{~Hz}$.

\section{Conclusions}

Suspension bridges are affected by the loads like temperature changes, traffic, pedestrian and wind. When designing the structure, all possible loads are considered. If it is necessary, these responses can be tested in a laboratory. But sometimes unexpected activities may occur on these kinds of structures. 
(a)

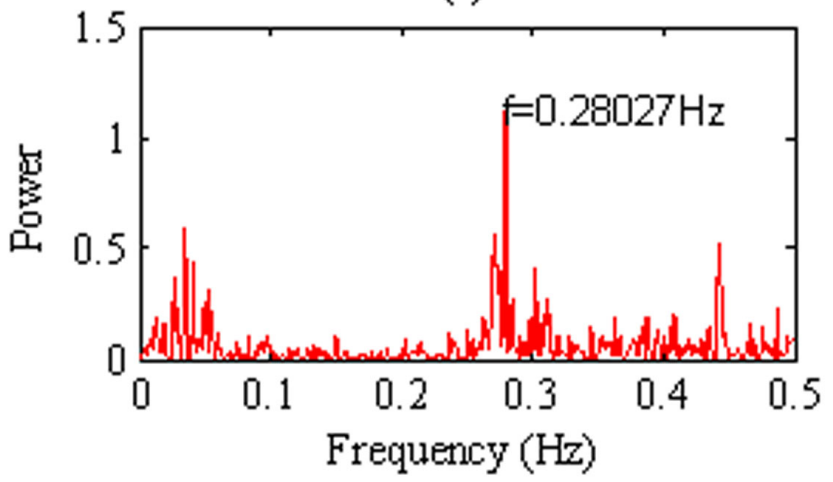

(b)

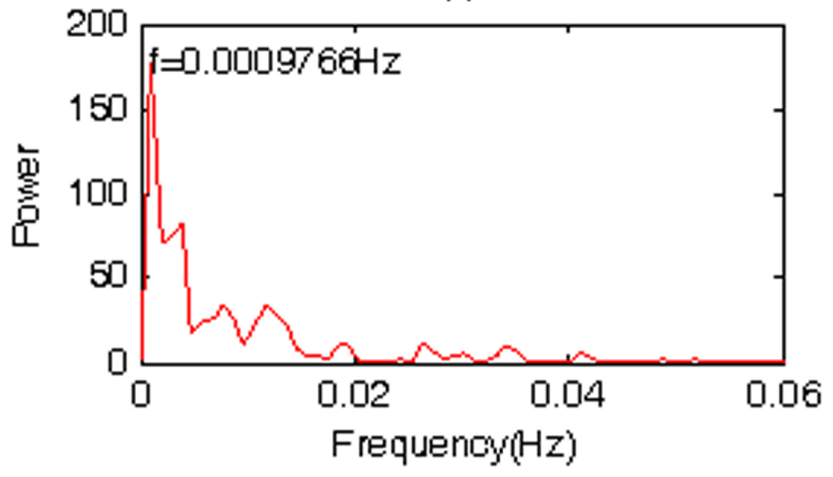

Fig. 6. High (a) and low (b) frequency values of the vertical component of the bridge's middle point which were obtained with the use of terrestrial observations (in the 1st phase of the project, the sampling frequency is $1 \mathrm{~Hz}$ ).

For example, the Eurasia Marathon is one good example of unexpected activity for the Bosporus Bridge, which was affected by different activities and loads such as rhythmic, systematic, and random pedestrian running during this event.

A lot of periodical movements were determined in this study at low frequency values of these periodical movements were $0.00036 \mathrm{~Hz}$ and $0.01172 \mathrm{~Hz}$ for each of the 12 parts. High frequencies were calculated as peak values of these frequencies were between $0.125-0.6 \mathrm{~Hz}$ and $0.75-1 \mathrm{~Hz}$ in the 4th part, $0-1 \mathrm{~Hz}$ in the 3rd part and $0-0.6 \mathrm{~Hz}$ and $0.75-1 \mathrm{~Hz}$ in other parts. However, continuously increasing vibrations were determined in the $3 \mathrm{rd}$ part. Frequency values in the $3 \mathrm{rd}$ part were bigger than frequency values in the other parts. It can be said that in this part the response of the bridge occurred because of the rhythmic running of the athletes. But there was no negative response on the bridge because of this short time effect.

Frequency values which were calculated from observations are in correspondence with the natural frequencies of the bridge. But it is impossible to obtain any information about the 9th mode frequency value $(0.677 \mathrm{~Hz})$, which was expected to be between $0.6 \mathrm{~Hz}-0.75 \mathrm{~Hz}$ in the frequency axes of the other parts except the 3rd part.

Also, the bridge behaved as above the mean level $(159 \mathrm{~mm})$ and below the mean level $(-390 \mathrm{~mm})$ when the traffic load was effective on the bridge. The other loads were less effective than the traffic load. So it was seen that the traffic load is effective for suspension bridge responses and these responses can be determined by RTK GPS observations, with a 2.2-centimeter vertical accuracy. Also, high sampling frequency $(10 \mathrm{~Hz})$ of the GPS is an important factor for determining the instantaneous vibrations on the bridge. This is important for determining the values and the number of natural frequencies which are necessary for determining the bridge's behaviors correctly.

A high sampling rate and high precision measurement equipment must be used to determine the instantaneous or high frequency responses of the suspension bridges, otherwise, enough information cannot be obtained about the structural behavior, and possible dangerous situations cannot be determined. But choosing the low sampling rates can be useful for determination of the long time changes (long time changes because of temperature changes). Thus, the measurement interval must be extended over a long time period.

Also, the time series which is obtained by observations of the responses under different loads can be analyzed on a time domain and frequency domain. If different loads do not affect the structure, it can be seen that the structural behavior matches the expected behavior. On the other hand, a priori information about the structural behavior can be obtained. For detailed information about the structure, not only the responses of the structure but also the effective loads must be observed and a mathematical model of the structure must be formed. These types of analyses are possible with parametric methods and in addition the response values, material parameters of the structure are studied and the model can be calibrated and defined.

Acknowledgements. This study was performed in the scope of the YTU BAPK project, numbered 25/05/2003-02, and named "Monitoring the Behaviors of Suspension Bridges under Internal and External Loads by Continuously Measurement Methods". We appreciate to Yildız Technical University, Coordinator of Science and Research Projects who supported the project. And also thanks to Directorate of 17th Distinct of Highways, Research Assistants F. Poyraz, N. O. Aykut and T. Ocalan for their support during the study.

Edited by: A. Tsonis

Reviewed by: two anonymous referees

\section{References}

Allen, R., L. and Mills, D., W.: Signal Analysis, Time, Frequency, Scale, and Structure, IEEE Press, USA, 2004.

Box, G. E. P. and Jenkins, G. M.: Time Series Analysis, Forecasting and Control, San Francisco, 1970. 
Chatfield, C.: The Analysis of Time Series, Chapman \& Hall/CRC, 1996.

Cheng, P., John, W., and Zheng, W.: Large Structure Health Dynamic Monitoring Using GPS Technology, FIG XXII International Congress, Washington, D.C. USA, 2002.

Dumanoğlu, A. A. and Severn, R. T.: Asynchronous Seismic Analysis of Modern Suspension Bridges, Part 1: Free Vibration, University of Bristol, Bristol, 1985.

Dumanoğlu, A. A. and Severn, R. T.: Seismic Response of Modern Suspension Bridges to Longitudinal and Lateral Ground Motion, Proc. Instn. Civ. Engrs., Part 2, Vol. 87, p. 73-86, 1989.

Erdoğan, H., Gülal, E., Ata, E., and Akpınar, B.: Mühendislik Yapılarına Etkiyen Büyüklüklerin Modellenmesi, Harita ve Kadastro Mühendisleri Odası, Mühendislik Ölçmeleri STB Komisyonu, 2. Mühendislik Ölçmeleri Sempozyumu, ITÜ - Istanbul, 2005.

Heunecke, O.: Ingenieurgeodatische Beitrage zur Überwachung von Bauwerken, Worhshop Dynamische Probleme-Modellierung und Wirklichkeit, Proceeding, pp. 159-176, 2000.

Kuhlmann, H.: Ein Beitrag zur Überwachung von Brückenbauwerken mit kontinuierlich registrierten Messungen. Wissenschaftliche Arbeiten der Fachrichtung Vermessungswesen der Universität Hannover, No. 218, 1996.

Kuhlman, K.: Importance of Autocorrelation for Parameter Estimation in Regression Models, Theory and Deformation Analysis, The 10th International Symposium on Deformation Measurements, California, 2001.

Lovse, J. W. , Teskey, W. F., Lachapelle, G., and Cannon, M. E.: Dynamic Deformation Monitoring of Tall Structure Using GPS Technology, J. Surv. Eng., Vol. 121(1), 16-22, 1995.
Roberts, G. W., Dodson, A. H., Ashkenozi, V. Brown, C. V., and Karuna, R.: Comparison of GPS Measurements and Finite Element Modelling for the Deformation Measurements of the Humber Bridge, Proc ION GPS, Nashville, USA, 1999.

Roberts, G. W., Meng, X., and Dodson, A.: Structural Dynamic and Deflection Monitoring Using Integrated GPS and Triaxial Accelerometer, The 13th International Technical Meeting of the satellite Division of the Institute of Navigation, USA, 2000.

Roberts, G. W., Meng, X., and Dodson, A. H.: The Use of Kinematic GPS and Triaxial Accelerometers to Monitor the Deflections of Large Bridges, 10th International Symposium on Deformation Measurements, California, USA, 2001.

Welsch, M. W. and Heunecke, O.: Models and Terminology For the Analysis of Geodetic Monitoring Observations, Official Report of the Ad-Hoc Committee of FIG Working Grup 6.1, p.21, 2001.

Welsch, W., Heunecke, O., and Kuhlmann, H.: Auswertung geodätischer Überwachungsmessungen, 510 pp. Wichmann Verlag, Heidelberg, 2000.

Wong, K. Y.: Planning and Implementation of the Structural Health Monitoring System for Cable-Supported Bridges in Hong Kong, Proceeding of SPIE, 3395, 266-276, 2000.

Yong, C. and Chrzanowski, A.: Identification of Deformation Models in Space and Time Domain, Survey Review, 33, (262 October), 1996. 